OPEN ACCESS

ISSN 2528-4649 (online) ISSN 2338-4409 (print)

Reviewed by: Wisnu Panggah Setiyono \& Irwan Moridu \& Zarah Puspitaningtyas

${ }^{\star}$ Correspondence:

Received: 27 Juli 2020 Accepted: 26 Agustus 2020 Published: 30 September 2020

Citation:

Marta Fiona SA and Mochamad

Trenggana AF (2020) Kinerja Keuangan Perusahaan Sebelum dan Sesudah Akuisisi (Studi pada

Industri Tambang Batubara Go

Public di Indonesia).

JBMP. 6:2.

doi: 10.21070/jbmp.v6i2.730

\section{Kinerja Keuangan Perusahaan Sebelum dan Sesudah Akuisisi (Studi pada Industri Tambang Batubara Go Public di Indonesia)}

\author{
Sri Anggeny Marta Fiona, Arlin Ferlina Mochamad Trenggana \\ Fakultas Komunikasi \& Bisnis, Universitas Telkom, Indonesia
}

In the last decade the development of coal prices are fluctuating, causing disruption to the company's financial and operational performance, massive layoffs, and the decline in coal stock prices. Seeing this situation, some companies make acquisitions or takeover of company ownership. The purpose of this study is to see how financial performance is compared before and after the acquisition using the Du Pont System, which includes the calculation of Return on Assets (ROA), Return On Equity (ROE), Net Profit Margin (NPM), Total Assets Turn Over (TATO), and Financial Leverage Multiplier (FLM). The study was using a comparative descriptive method with a quantitative approach. The object of the research is the coal mining industry went public in Indonesia which made an acquisition in 2016, with a population of 22 companies and sampling based on certain criteria consisting of 2 companies using the Du Pont System analysis in secondary data processing. Based on the analysis, although overall financial performance after acquisition has increased, referring to the results of paired sample t-test showed no significant differences in financial performance before and after the acquisition, because the test results showed a significance value greater than $0.05 \mathrm{so} \mathrm{HO}$ is accepted.

Keywords: Comparison of financial performance, ROA, ROE, NPM, TATO, FLM

Dalam satu dekade terakhir perkembangan harga batubara terus mengalami fluktuasi, sehingga berdampak buruk bagi para pelaku bisnis, diantaranya terganggunya kinerja keuangan dan operasional perusahaan, terjadi PHK besar-besaran, hingga menurunnya harga saham batubara. Melihat dampak buruk yang terjadi, beberapa perusahaan melakukan akuisisi atau pengambil alihan kepemilikan perusahaan. Tujuan penelitian ini adalah melihat bagaimana perbandingan kinerja keuangan sebelum dan sesudah akuisisi dengan menggunakan Du Pont System, yang mencakup perhitungan Return On Assets (ROA), Return On Equity (ROE), Net Profit Margin (NPM), Total Assets Turn Over (TATO), dan Financial Leverage Multiplier (FLM). Penelitian dilakukan menggunakan metode deskriptif komparatif dengan pendekatan kuantitatif. Objek penelitian adalah industri tambang batubara go public di Indonesia yang melakukan akuisisi di tahun 2016, dengan populasi 22 perusahaan dan pengambilan sampel berdasarkan kriteria tertentu terdiri 2 perusahaan menggunakan analisis Du Pont System dalam pengolahan data sekunder. Berdasarkan analisis yang dilakukan, meski kinerja keuangan sesudah akuisisi secara keseluruhan mengalami peningkatan, merujuk hasil uji paired sampel ttest memperlihatkan tidak terdepat perbedaan signifikan pada kinerja keuangan sebelum 
dan sesudah akuisisi dilakukan, karena hasil uji test memperlihatkan nilai signifkansi lebih besar dari 0,05 sehingga $\mathrm{HO}$ diterima.

Kata Kunci : Perbandingan kinerja keuangan, ROA, ROE, NPM, TATO, FLM 


\section{PENDAHULUAN}

Dalam satu dekade terakhir perkembangan harga batubara terus mengalami fluktuasi. Sehingga berdampak buruk bagi para pelaku bisnis. Berbagai dampak yang terjadi diantaranya ialah terganggunya kinerja keuangan dan operasional perusahaan, turunnya nilai ekspor batubara, terjadi PHK besarbesaran, hingga menurunnya harga saham batubara. Melihat dampak buruk yang terjadi, beberapa perusahaan melakukan upaya dalam menyelamatkan industri tambang batubara agar tetap terus berjalan. Salah satu upaya yang dilakukan ialah dengan melakukan akuisisi.

Akuisisi merupakan pengambil alihan kepemilikan atau pengendalian atas saham atau aset suatu perusahaan oleh perusahaan lain, dan dalam peristiwa ini baik perusahaan pengambilalihan atau yang diambil alih tetap eksis sebagai badan hukum yang terpisah (Serfiyani dkk, 2017). Tindakan melakukan akuisisi dianggap sebagai solusi terbaik karena dinilai lebih minim risiko dan juga lebih minim biaya bagi sebuah perusahaan (Kamaludin, 2010:131) dalam Hapsari (2016). Di tahun 2016 sendiri, kondisi perekonomian yang lesu berakibat pada maraknya konsolidasi bisnis baik merger maupun akuisisi. Bahkan nilai transaksi merger dan akuisisi di Indonesia di tahun 2016 mengalahkan rekor nilai merger dan akuisisi tahun 2013 yang sekitar US\$ 10 miliar.

Beberapa penelitian sebelumnya tentang perbandingan kinerja keuangan perusahaan antara sebelum dan sesudah akuisisi dengan variabel operasional yang sama memperlihatkan hasil yang beragam. Diantarnya Long Hoang Pham (2014) menemukan tidak terdapat perbedaan yang signifikan pada Return on Assets dan Net Profit Margin antara sebelum dan sesudah akuisisi. Neelam Rani dan Surendra (2013) menemukan terdapat perbedaan yang signifikan pada Return On Assets antara sebelum dan sesudah akuisisi. Dalam melihat apakah tindakan sebuah akuisisi berhasil atau tidak, dapat dilakukan dengan analisis kinerja keuangan. Apabila posisi keuangan perusahaan pasca akuisisi lebih baik dari sebelum akuisisi maka perusahaan tersebut mengalami perubahan positif. Untuk menganalisis kinerja keuangan, dalam penelitian ini menggunakan $D u$ Pont System.

Du Pont System adalah salah satu alat ukur yang dipakai untuk menganalisis laporan keuangan. Menurut Harahap (2013 : 334-335) dalam Nurahma (2016) Du Pont System menggunakan beberapa rasio keuangan yang merupakan kumpulan dari beberapa rasio diantaranya rasio profitabilitas, rasio aktivitas dan rasio solvabilitas. Dalam metode ini, analisis kinerja keuangan dilakukan dengan memecah atau menjabarkan ROE (Return on Equity) dan ROA (Return on Assets) ke dalam beberapa rasio penting untuk mengukur kemampuan perusahaan dalam memperoleh keuntungan, dengan menghubungkan antara keuntungan atau laba yang diperoleh perusahaan dari kegiatan pokok dengan kekayaan atau aset yang digunakan untuk menghasilkan keuntungan tersebut.

Berdasarkan latar belakang yang dipaparkan dan adanya inkonsistensi pada penelitian-penelitian sebelumnya oleh sebab itu peneliti tertarik dalam melakukan penelitian dengan judul: "Kinerja Keuangan Perusahaan Sebelum dan Sesudah Akuisisi (Studi pada Industri Tambang Batubara Go Public di Indonesia) ". Dengan tujuan akhir memaparkan bagaimana kinerja keuangan sebelum dan sesudah akuisisi menggunakan Du Pont System hingga menjelaskan bagaimana perbandingan kinerja keuangan sebelum dan sesudah akuisisi pada industri tambang batubara go public di Indonesia.

\section{METODE}

\section{Tinjauan Pustaka}

Akuisisi perusahaan secara sederhana dapat diartikan sebagai pengambilalihan perusahaan dengan cara membeli saham mayoritas perusahaan sehingga menjadi pemegang saham pengendali. Dalam peristiwa akuisisi, perusahaan yang mengambil alih (pengakuisisi) tetap hidup sebagai badan hukum yang terpisah dengan perusahaan yang diambil alih (diakuisisi) (Serfiyani dkk, 2017).

Du Pont merupakan suatu analisis terstruktur dari laporan keuangan yang digunakan untuk menilai kondisi keuangan perusahaan. Keown et al (2005:86) dalam Hapsari (2016), menyatakan bahwa "analisis Du Pont merupakan metode yang digunakan untuk menganalisis profitabilitas perusahaan dan return on equity". Gitman (2009:75) dalam Hapsari (2016), berpendapat tentang penggunaan Du Pont, yaitu: Du Pont system dilakukan dengan tujuan membedah laporan keuangan perusahaan dan untuk menilai kondisi keuangan. Menggabungkan laporan laba rugi dan neraca menjadi ukuran ringkas profitabilitas : Return on Total Asset (ROA) dan Return on Equity (ROE).

Untuk menilai kondisi keuangan dan kinerja perusahaan, angka-angka yang terdapat pada laporan keuangan akan jadi lebih bermakna jika angka-angka tersebut saling dibandingkan, salah satunya dapat menggunakan rasio keuangan. Menurut Hery (2017:138) rasio keuangan merupakan suatu perhitungan rasio dengan menggunakan laporan keuangan yang berfungsi sebagai alat ukur dalam menilai kondisi keuangan dan kinerja perusahaan. Beberapa rasio yang yang digunakan dalam penelitian ini ialah :
1. Return on Assets
2. Return on Equity
3. Net Profit Margin
4. Total Assets Turn Over
5. Financial Leverage Multiplier

\section{Jenis Penelitian}

Penelitian ini dikategorikan sebagai penelitian deskriptif komparatif menggunakan pendekatan kuantitatif, dengan menggambarkan secara sistematis mengenai fakta-fakta yang ada serta menguji kebenaran dari suatu hipotesis dengan cara 
mengumpulkan data, mengolah, menganalisis, dan menginterprestasikan data dalam pengujian hipotesis secara statistic.

\section{Populasi \& Sampel}

Populasi dalam penelitian ini adalah industri tambang batubara di Indonesia, dengan penentuan sampel yang merujuk pada kriteria yaitu perusahaan tambang batubara go public yang melakukan akuisisi di tahun 2016. Berdasarkan kriteria tersebut, dari penelusuran yang dilakukan peneliti dari berbagai sumber didapatkan dua perusahaan tambang batubara yang memenuhi kriteria yakni PT Adaro Energy Tbk. yang mengakuisisi BHP Billiton di PT Indo Met Coal (IMC) serta PT Golden Energy Mines Tbk yang mengakuisisi PT. Era Mitra Selaras pada tahun 2016 silam.

\section{Pengumpulan \& Sumber Data}

Teknik pengumpulan data yang digunakan dalam penelitian ini adalah dokumentasi dan studi kepustakaan, dengan menggunakan data sekunder :

1. Data yang berkaitan dengan Return on Assets, Return on Equity, Net Profit Margin, Total Assets Turn Over, dan Financial Leverage Multiplier yang didapat dari laporan keuangan tahunan PT. Adaro Energy Tbk. tahun 2014-2018 dan laporan keuangan tahunan PT. Golden Energy Mines Tbk. tahun 2014-2018.

2. Buku serta teori-toeri terkait dari beberapa orang ahli.

3. Penelitian sebelumnya yang mendukung penelitian ini, dapat berbentuk jurnal, skripsi, maupun artikel

\section{Teknik \& Metode Analisis Data}

Teknik analisis data yang digunakan adalah Du Pont System, dengan metode analisis data menggunakan Paired Sample Ttest. Sebelum dilakukan uji perbedaan dua nilai rata-rata, terlebih dahulu dilakukan uji normalitas untuk melihat apakah data yang diperoleh berdistribusi normal atau tidak, dimana kedua buah pengujian ini dilakukan dengan menggunakan aplikasi program SPSS.

\section{HASIL DAN PEMBAHASAN}

\section{Kinerja Keuangan Industri Tambang Batubara Sebelum Akuisisi}

[Table 1 about here.]

Berdasarkan tabel diatas, dapat dilihat bahwa secara keseluruhan kinerja keuangan di tahun 2015 mengalami penurunan dibandingkan tahun sebelumnya, meski ada satu buah rasio yaitu FLM yang juga mengalami peningkatan. Dari kelima rasio yang diteliti, ROA, ROE dan NPM berada dibawah ratarata sampel $(357892,4)$, yang berarti kinerja keuangan sebelum akuisisi dinilai kurang baik dan kurang efisien. Sementara untuk TATO dan FLM yang berada diatas rata-rata sampel, berarti kinerja keuangan sebelum akuisisi dinilai baik dan efisien.

\section{Kinerja Keuangan Industri Tambang Batubara Sesudah Akuisisi}

[Table 2 about here.]

Merujuk pada tabel diatas, dapat dilihat bahwa secara keseluruhan kinerja keuangan di tahun 2018 mengalami penurunan dibandingkan tahun sebelumnya, meski ada satu buah rasio yaitu TATO yang juga mengalami peningkatan. Dari kelima rasio yang diteliti, ROA, ROE dan TATO berada dibawah ratarata sampel $(959269,2)$, yang berarti kinerja keuangan sesudah akuisisi dinilai kurang baik dan kurang efisien. Sementara untuk NPM dan FLM yang berada diatas rata-rata sampel, berarti kinerja keuangan sesudah akuisisi dinilai baik dan efisien

\section{Perbandingan Kinerja Keuangan Industri Tambang Batubara Sebelum dan Sesudah Akuisisi}

\author{
[Table 3 about here.]
}

Meski kinerja keuangan sesudah akuisisi secara keseluruhan memperlihatkan adanya peningkatan, namun berdasarkan hasil uji paired sampel t-test diketahui perbedaan kinerja keuangan sebelum dan sesudah akuisisi tidak memperlihatkan hasil yang signifikan karena nilai signifikansi masing-masing rasio yang lebih besar dari 0,05 sehingga $\mathrm{H} 0$ diterima. Hal ini berarti kemampuan industri tambang batubara dalam meningkatan kinerja keuangan pasca dilakukannya akuisisi belum signifikan dan dinilai masih kurang baik dan kurang efisien.

Beberapa penelitian terdahulu dengan menggunakan variabel operasional yang sama memperlihatkan hasil yang serupa, bahwa tidak terdapat perbedaaan yang signifikan pada kinerja keuangan sebelum dan sesudah akuisisi dilakukan, diantaranya Putu Yulia dkk (2018), Satrya Darma dkk (2016) serta Ira Aprilita dkk (2015).

Hasil penelitian yang menunjukkan tidak adanya perbedaan signifikan pada kinerja keuangan perusahaan sesudah akuisisi menjelaskan bahwa motif perusahaan dalam melakukan strategi akuisisi bukanlah motif ekonomi melainkan non ekonomi. Menurut Aulina (2012) dalam Dewi (2018) motif-motif non ekonomi yang mendasari kegiatan akuisisi antara lain seperti kurangnya keterampilan manajemen perusahaan yang akan diakuisisi, atau karena keinginan untuk menjadi kelompok perusahaan yang besar.

Selain itu, penyebab lainnya adalah periode penelitian yang hanya melihat perubahan kinerja keuangan dua tahun sebelum dan dua tahun sesudah, sementara manfaat ekonomis 
dari akuisisi tidak hanya dapat dilihat dalam jangka waktu pendek melainkan dibutuhkan waktu jangka panjang untuk meningkatkan kinerja keuangan perusahaan sehingga tercapai sinergi dengan perusahaan yang diakuisisi

\section{KESIMPULAN}

Berdasarkan metode analisis du pont, kinerja keuangan industri tambang batubara sebelum melakukan akuisisi adalah sebagai berikut, ROA dengan rata-rata 2,3375, ROE dengan ratarata 3,815, NPM dengan rata-rata 0,8204, TATO dengan ratarata 0,1194 serta FLM dengan rata-rata 1,648145. Sedangkan kinerja keuangan industri tambang batubara sesudah melakukan akuisisi adalah sebagai berikut, ROA meningkat dengan rata-rata 12,305 , ROE meningkat dengan rata-rata 24,2, NPM meningkat dengan rata-rata 6,434075, TATO meningkat dengan rata-rata 0,942 serta FLM yang juga meningkat dengan rata-rata 1,727825 . Merujuk pada hasil analisis yang dilakukan, meski kinerja keuangan sesudah akuisisi secara keseluruhan mengalami peningkatan, namun meru- juk pada hasil uji paired sampel t-test memperlihatkan bahwa tidak terdepat perbedaan yang signifikan pada kinerja keuangan sebelum dan sesudah akuisisi dilakukan, hal ini karena hasil uji test memperlihatkan nilai signifkansi yang lebih besar dari 0,05 sehingga $\mathrm{H} 0$ diterima.

\section{UCAPAN TERIMA KASIH}

Terimakasih tiada tara kepada Allah swt. yang selalu memberikan kekuatan dalam penyelesaian penelitian ini dan telah meridhoi penyelesaian penelitian ini. Teruntuk mama, papa, abang, ajo dan kakak yang selalu mendoakan serta memberi support juga mempercayai bahwa apapun yang terjadi peneliti dapat segera menyelesaikan penelitian ini dengan baik. Kepada dosen pembimbing Ibu Arlin Ferlina Mochamad Trenggana yang selalu membimbing juga menyemangati serta memberikan pencerahan dalam kendala-kendala yang dihadapi selama penelitian. Lalu kepada Nurhayana Thoybah, selaku sahabat yang mendoakan dan senantiasa menjadi tempat bercerita serta selalu mengingatkan agar tetap semangat.

\section{REFERENSI}

Hapsari, S. (2016). Analisis Perbedaan Kinerja Keuangan Perusahaan Sebelum dan Sesudah Merger (Kasus pada Bank CIMB Niaga yang terdaftar di BEI). Jurnal Ekonomi dan Bisnis.

Harahap, S. S. (2018). Analisis Kritis atas Laporan Keuangan . Depok: Rajawali Pers.

Hery. (2017). Analisis Laporan Keuangan. Jakarta: Gramedia Widiasarana.

Nurrahma. (2016). Analisis Kinerja Keuangan Perusahaan dengan Menggunakan Metode Dupont System untuk Sub Sektor Pertambangan Batubara yang Listing di Bursa Efek Indonesia Periode 2008-2014. Jurnal Komunikasi dan Bisnis, 10.

Rachmawati, A. (2015). Analisis Perbedaan Kinerja Keuangan PT. Surya Citra Media Tbk. dan PT. Media Nusantara Citra Tbk. Selama Periode 2008-2013. Jurnal Komunikasi dan Bisnis, 9.

Serfiyani, C. Y. (2017). Restrukturisasi Perusahaan. Yogyakarta: Andi.

\begin{abstract}
Conflict of Interest Statement: The authors declare that the research was conducted in the absence of any commercial or financial relationships that could be construed as a potential conflict of interest.
\end{abstract}

Copyright (c) 2020 Marta Fiona and Mochamad Trenggana. This is an open-access article distributed under the terms of the Creative Commons Attribution License (CC $B Y)$. The use, distribution or reproduction in other forums is permitted, provided the original author(s) and the copyright owner(s) are credited and that the original publication in this journal is cited, in accordance with accepted academic practice. No use, distribution or reproduction is permitted which does not comply with these terms. 


\section{LIST OF TABLES}

Kinerja KeunganIndustri Tambang Batubara periode $2014-2015$. . . . . . . . . . . . . . . . . . . 72

Kinerja Keungan Industri Tambang Batubara periode 2017-2018 . . . . . . . . . . . . . . . . . . . . 73

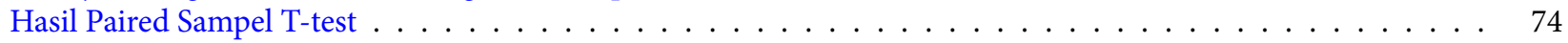


TABLE 1 | Kinerja Keunganlndustri Tambang Batubara periode 2014-2015

\begin{tabular}{llllll}
\hline Tahun & ROA & ROE & NPM & TATO & FLM \\
2014 & 3,15 & 4,97 & 1,31767 & 0,920345 & 1,620825 \\
2015 & 1,525 & 2,66 & 0,32313 & 0,703525 & 1,67546 \\
\hline
\end{tabular}

(sumber : hasil olahan peneliti,2020) 
TABLE 2 | Kinerja Keungan Industri Tambang Batubara periode 2017-2018

\begin{tabular}{llllll}
\hline Tahun & ROA & ROE & NPM & TATO & FLM \\
2017 & 14,035 & 26,93 & 7,99226 & 0,882285 & 1,842875 \\
2018 & 10,565 & 21,46 & 4,875885 & 1,001705 & 1,61277 \\
\hline
\end{tabular}

(sumber : hasil olahanpeneliti,2020 
TABLE 3 | Hasil Paired Sampel T-test

\begin{tabular}{lll}
\hline Variabel & Nilai t & Nilai Signifikansi \\
ROA & $-0,478$ & 0,716 \\
ROE & $-0,795$ & 0,572 \\
NPM & $-0,996$ & 0,501 \\
TATO & $-1,092$ & 0,472 \\
FLM & $-0,003$ & 0,998 \\
\hline
\end{tabular}

(sumber: hasil uji spss,2020) 